\title{
Enzyme levels in testis and other tissues of genetically sex-reversed mice
}

\author{
Janet T. Jones*, Sandra J. Andrews and B. M. Cattanach \\ Medical Research Council, Radiobiology Unit, Harwell, Didcot, Oxon. OX11 ORD, U.K.
}

\begin{abstract}
Summary. The specific activities of G6PD and PGK were measured in the testes, seminal vesicles, and livers of $S x r /+, X X$ mice, their $S x r /+, X Y$ littermates and normal mice. While G6PD activity was high in the testes of young normal mice and declined as the testes matured, in the testes of $S x r /+, \mathrm{XX}$ mice activity remained high, suggesting a failure of the Sertoli cells to mature normally. The activity of PGK was low in the testes of young normal mice, and increased as the testes matured. The testes of young $S x r /+, \mathrm{XX}$ mice had high activity of this enzyme which remained high into adulthood. The high activity in young mice suggests an abnormality in the somatic cells.

The seminal vesicle and liver measurements of G6PD and PGK confirmed that the $S x r /+, \mathrm{XX}$ mice were phenotypically normal males except with respect to the testis.

The developmental patterns of both enzymes in testes lacking germinal cells indicate that the maturation of the somatic cells of the normal testis is influenced by the presence of germinal cells.
\end{abstract}

\section{Introduction}

During the development of the testis of the normal mouse, marked changes in the levels of several different enzymes accompany the differentiation of both the germinal cells and the somatic cells (Shen \& Lee, 1976). In the period of development before puberty, the germinal cells proliferate and undergo meiosis and spermiogenesis. At the same time, the Sertoli cells form characteristic occluding junctions which are the structural basis of the blood-testis permeability barrier (Flickinger, 1967; Gilula, Fawcett \& Aoki, 1976). The Leydig cells also undergo changes which appear to be a de-differentiation followed by a re-differentiation (Gondos, 1977). These developmental changes are accompanied by an increase in the activity of some enzymes such as lactate dehydrogenase and sorbitol dehydrogenase, and a decrease in others such as glucose-6. phosphate dehydrogenase and malate dehydrogenase (Shen \& Lee, 1976).

The present study is concerned with developmental changes in the testes of mice without germinal cells. The mice used were of female (XX) chromosomal constitution, but showed a male phenotype due to the presence of an autosomal dominant factor, sex-reversed (Sxr: Cattanach, Pollard \& Hawkes, 1971). Animals of this genotype are phenotypically normal males, but the testes are small and lack germinal cells. The aim of the study was to determine how this germ cell-deficient testis differed from normal in growth and enzyme development, and whether the accessory sex glands were affected.

The two enzymes chosen for analysis show opposite changes in activity during the development of the normal testis. Glucose-6-phosphate dehydrogenase (G6PD, EC 1.1.1.49) decreases in activity with age in the testes of normal mice (Shen \& Lee, 1976) due to a decline in both

* Present address: Department of Biochemistry, University of Glasgow, Glasgow G12 8QQ, U.K. 
the proportion and enzyme activity of the Sertoli cells in the developing testis (Jones \& Andrews, 1978). Phosphoglycerate kinase (PGK, EC 2.7.2.3) increases in activity during the development of the normal testis (Erickson, 1977). There are two isoenzymes present in the testis, PGK A, which is characteristic of somatic tissues, and PGK B, which is found only in the testis, and appears at about the same time as the spermatids (Vandeberg, Cooper \& Close, 1976).

The testes of $S x r /+, \mathrm{XX}$ mice of various ages were compared to those of normal mice with respect to weight and to activity of the two enzymes, and the enzyme activity of adult seminal vesicles and liver was measured. Enzyme activity measurements were also made on XY mice which carried the $S x r$ factor.

\section{Materials and Methods}

\section{Animals}

The $S x r /+, \mathrm{XX}$ mice used, their $S x r /+, \mathrm{XY}$ littermates, and their normal littermates were from stocks maintained at the Unit (by B.M.C.) by crossing $S x r /+, \mathrm{XY}$ males to $\mathrm{F}_{1}$ hybrid (3H1) females derived from the cross $\mathrm{C} 3 \mathrm{H} / \mathrm{HeH} \times 101 / \mathrm{H}$ inbred strains. In the studies on young animals the X-linked marker tabby $(T a)$ was employed to allow $S x r /+, \mathrm{XX}$ individuals to be identified by the tabby striping in their coats. The control mice in these studies were $3 \mathrm{H} 1$ hybrids. The genotypes of adult animals were determined by the testis weight. It has been shown by Cattanach (1975) that the $S x r$ factor affects the testis weight: $S x r /+, \mathrm{XX}$ animals have a paired testis weight of less than $60 \mathrm{mg}, S x r /+, \mathrm{XY}$ animals have a range from 100 to $204 \mathrm{mg}$ and $+/+, X Y$ animals have testes of $180-240 \mathrm{mg}$. In our series, animals with testis weights between 180 and $200 \mathrm{mg}$ were not used.

\section{Enzyme assays}

Tissues for enzyme activity analysis were extracted in 30 times their own weight of $0.9 \%$ (w/v) $\mathrm{NaCl}+0.6 \mathrm{~mm}$-EDTA. They were homogenized for $30 \mathrm{sec}$ in an Ultra-Turrax homogenizer. The extracts were then centrifuged for $30 \mathrm{~min}$ at $45000 \mathrm{~g}$, and the supernatants were used in the enzyme assay. Enzymes were assayed by the methods of Bergmeyer (1974). The reaction mixtures were as indicated below.

G6PD: 39 mM-triethanolamine buffer, pH 7.5; 3.9 mM-EDTA; 0.5 mM-NADP (made up at $25 \mathrm{mg} / \mathrm{ml}$ in $1 \% \mathrm{NaH} \mathrm{CO}_{3}$ ); and $0.67 \mathrm{~mm}$-glucose-6-phosphate.

PGK: 78.3 mM-triethanolamine buffer, pH 7.6; 0.9 mM-EDTA; 0.2 mM-NADH; 1.1

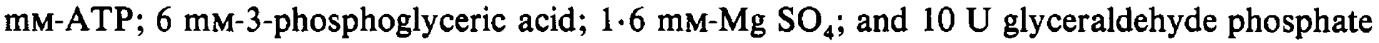
dehydrogenase $/ \mathrm{ml}$.

All reagents were supplied by Sigma London (Poole, Dorset, U.K.), except EDTA and $\mathrm{MgSO}_{4}$ which were supplied by B.D.H. (Poole, Dorset, U.K.). The reactions were carried out in a volume of $0.7 \mathrm{ml}$ in a cuvette with a $1 \mathrm{~cm}$ light path. The linear change in absorbance at 340 $\mathrm{nm}$ was measured in a Pye-Unicam SP 800 spectrophotometer, and the activity was expressed as $\mu \mathrm{mol}$ NADP reduced $/ \mathrm{min} / \mathrm{mg}$ protein for G6PD, and as $\mu \mathrm{mol} \mathrm{NADH}$ oxidized $/ \mathrm{min} / \mathrm{mg}$ protein for PGK. Protein determinations were by the method of Lowry, Rosebrough, Farr \& Randall (1951), as modified by Hartree (1972).

\section{Results}

Text-figure 1 shows the increase in testis weight with age in $S x r /+, \mathrm{XX}$ mice compared with that of normal $3 \mathrm{H} 1$ males. The small testis size of the $S x r /+, \mathrm{XX}$ mice was pronounced and the difference in testis weight was apparent by approximately 12 days of age. The testes of these mice reached adult weight by about 30 days, compared with about 40 days in normal mice, The specific activity of G6PD remained high in the testes of $S x r /+, \mathrm{XX}$ mice, even when maximum size was reached (Text-fig. 2; Table 1). 


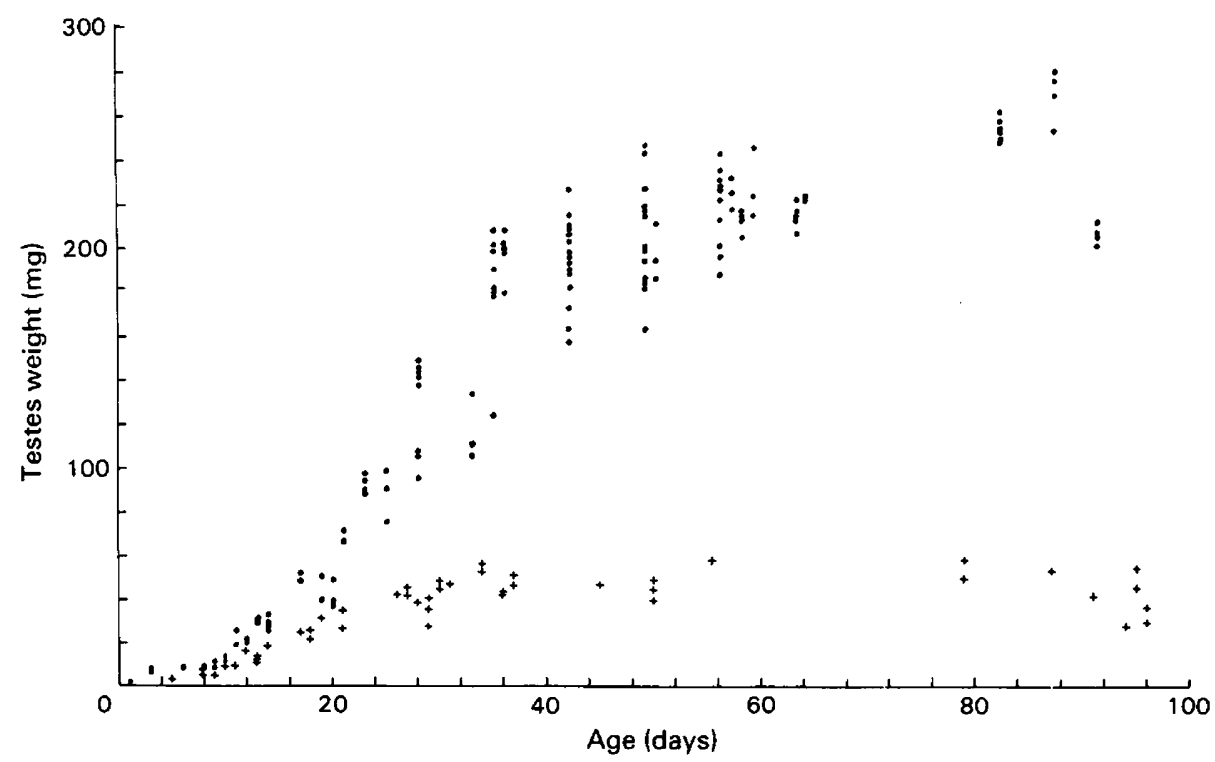

Text-fig. 1. Paired testicular weight changes with age in $S x r /+, \mathrm{XX}$ mice (+) compared with those of normal $3 \mathrm{H} 1$ males (O).

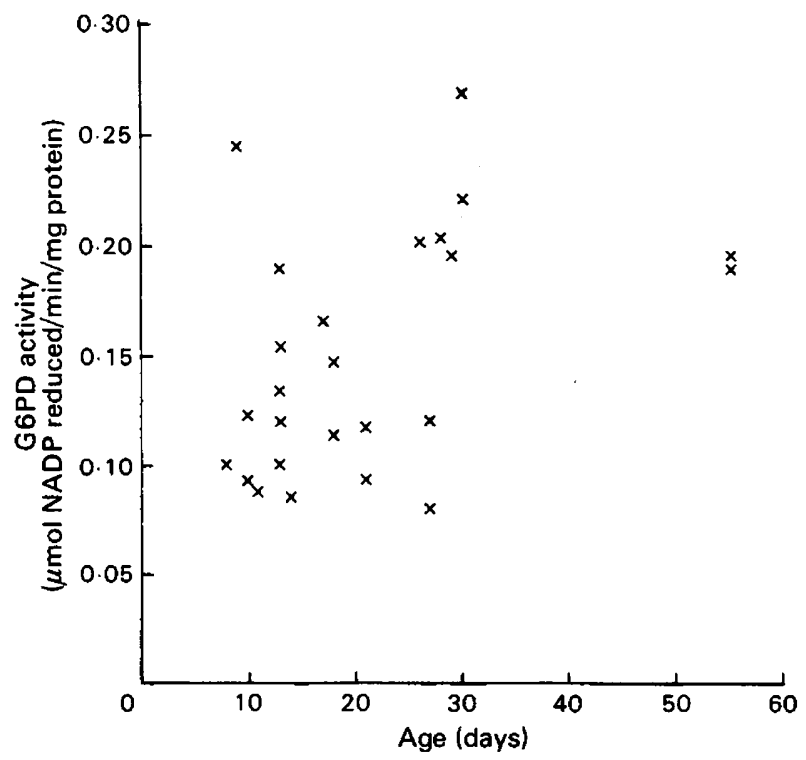

Text-fig. 2. Specific activity of glucose-6-phosphate dehydrogenase in the developing testis of $\mathrm{Sxr} /+, \mathrm{XX}$ mice.

The activity of PGK increased markedly between the ages of 30 and $\mathbf{4 0}$ days in normal mice (Text-fig. 3a), but was elevated in the testes of young $S x r /+, \mathrm{XX}$ mice and remained high into adulthood (Text-fig. 3b). For mice younger than 30 days, the testis PGK activity for $\mathrm{Sxr} /+, \mathrm{XX}$ mice was both significantly higher and significantly more variable than for normal testes, but after $\mathbf{4 0}$ days of age, the values were similar to those for normal adult mice (Table 1). 


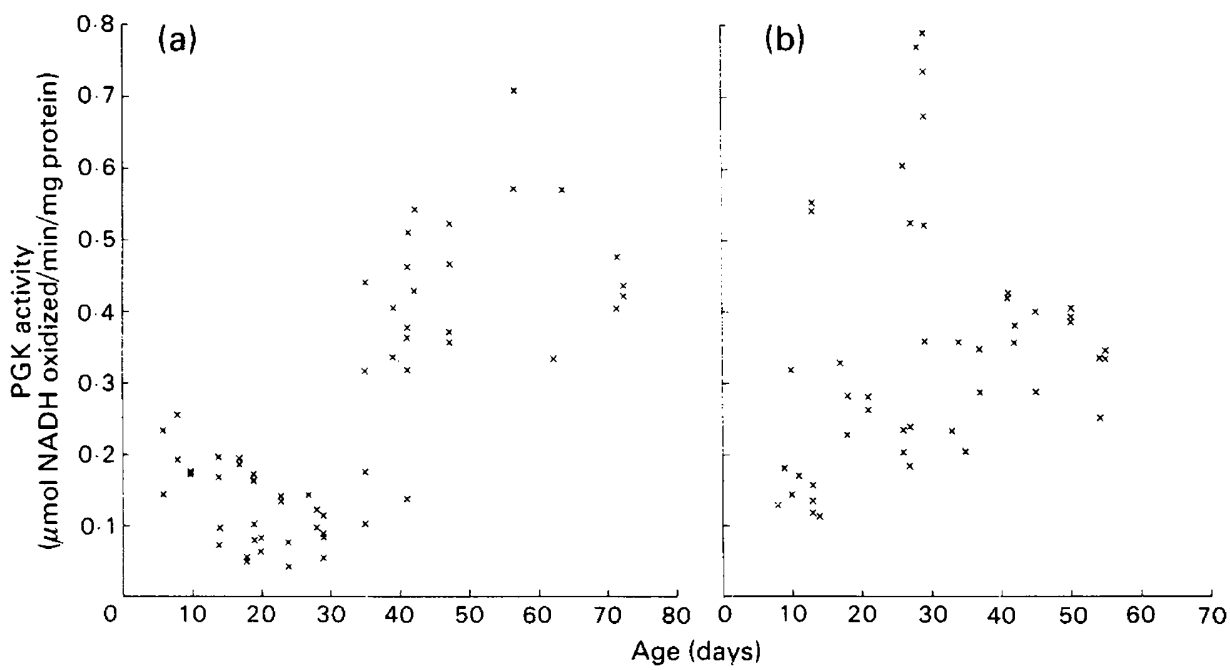

Text-fig. 3. Specific activity of phosphoglycerate kinase in the developing testes of (a) normal $3 \mathrm{H} 1$ mice and (b) $S x r /+, \mathrm{XX}$ mice.

Table 1. Mean \pm s.e.m. activity of glucose-6-phosphate dehydrogenase (G6PD) and phosphoglycerate kinase (PGK) in the testes of normal and $S x r /+, \mathrm{XX}$ mice (no. in parentheses)

\begin{tabular}{llccc}
\hline Enzyme & Age & $S x r /+, \mathrm{XX}$ & $+/+, \mathrm{XX}$ & $\begin{array}{c}\text { Significanceq } \\
\text { (Student's } t \text { test) }\end{array}$ \\
\hline G6PD* & Young (<20 days) & $0.134 \pm 0.012(14)$ & $0.0986 \pm 0.0082(16) \ddagger$ & $P<0.017$ \\
& Adult $(>20$ days) & $0.146 \pm 0.013(20)$ & $0.0574 \pm 0.0038(11) \S$ & $P<0.0001$ \\
PGK $\dagger$ & Young (<30 days) & $0.352 \pm 0.043(27)$ & $0.128 \pm 0.010(32) \ddagger$ & $P<0.0001$ \\
& Adult ( $>40$ days) & $0.350 \pm 0.018(22)$ & $0.438 \pm 0.023(28) \S$ & $P<0.11$ \\
\hline
\end{tabular}

* Values expressed as $\mu \mathrm{mol}$ NADP reduced $/ \mathrm{min} / \mathrm{mg}$ protein.

$\dagger$ Values expressed as $\mu \mathrm{mol}$ NADH oxidized $/ \mathrm{min} / \mathrm{mg}$ protein.

$\ddagger 3 \mathrm{H} 1$ mice.

$\S 3 \mathrm{H} 1$ mice and $+/+, \mathrm{XY}$ littermates of sex-reversed mice.

I Probability that the means for $S x r /+, \mathrm{XX}$ mice are the same as those for normal mice.

Enzyme activity measurements in various organs of $S x r /+, \mathrm{XX}$ mice and their normal and $S x r /+, \mathrm{XY}$ littermates are shown in Table 2 . Liver was used as a control organ as it is unrelated to sex differentiation. In only one comparison (testicular G6PD) was the difference between the groups of animals significant.

Table 2. Mean \pm s.e.m. (no. in parentheses) activity of glucose-6-phosphate dehydrogenase (G6PD) and phosphoglycerate kinase (PGK) in the testis, seminal vesicle and liver of adult (56-96 days) $S x r /+, \mathrm{XX}$ mice and their $S x r /+, \mathrm{XY}$ and normal littermates.

\begin{tabular}{lllll}
\hline Enzyme & \multicolumn{1}{c}{ Organ } & \multicolumn{1}{c}{$S x r /+, \mathrm{XX}$} & \multicolumn{1}{c}{$S x r /+, \mathrm{XY}$} & $+/+, \mathrm{XY}$ \\
\hline G6PD $\dagger$ & Testis & $0.1283 \pm 0.0148(11)$ & $0.0792 \pm 0.0096(8)$ & $0.0546 \pm 0.0052(7)$ \\
& Seminal vesicle & $0.0768 \pm 0.0092(8)$ & $0.0697 \pm 0.0074(6)$ & $0.0687 \pm 0.0096(7)$ \\
& Liver & $0.0117 \pm 0.0028(9)$ & $0.0080 \pm 0.0021(6)$ & $0.0067 \pm 0.0014(7)$ \\
PGK $\neq$ & Testis & $0.3323 \pm 0.0329(11)$ & $0.4637 \pm 0.0593(9)$ & $0.4298 \pm 0.0476(8)$ \\
& Seminal vesicle & $0.3366 \pm 0.0497(8)$ & $0.3069 \pm 0.053(6)$ & $0.2753 \pm 0.046(7)$ \\
& Liver & $0.9307 \pm 0.159(9)$ & $0.6099 \pm 0.159(6)$ & $0.5242 \pm 0.0859(7)$ \\
\hline
\end{tabular}

* Significantly different from values for $S x r /+, \mathrm{XY}$ and $+/+, \mathrm{XY}$ mice, $P<0.0002$ (Student's $t$ test).

$\dagger$ Expressed as $\mu \mathrm{mol}$ NADP reduced $/ \mathrm{min} / \mathrm{mg}$ protein.

$\ddagger$ Expressed as $\mu \mathrm{mol}$ NADH oxidised $/ \mathrm{min} / \mathrm{mg}$ protein. 


\section{Discussion}

In considering the differences in testicular enzyme activity between $S x r /+, \mathrm{XX}$ and normal mice, it must be borne in mind that the cellular compositions of the testes of the two kinds of animal are vastly different. The testis of $S x r /+, \mathrm{XX}$ mice contains gonocytes at birth, but by about 5 days of age there are no germ cells (Cattanach et al., 1971) and all the cells present, Leydig, Sertoli and peritubular cells, are of somatic origin. The normal testis, in contrast, becomes progressively richer in germinal cells as the testis matures. At 6 days, the seminiferous epithelium consists of $84 \%$ Sertoli cells and $16 \%$ spermatogonia, but by 20 days, there are only $28 \%$ Sertoli cells, the rest of the seminiferous epithelium being germinal cells of various stages up to round spermatids (Bellvé et al., 1977). Therefore, our comparisons of enzyme activities in the testes of $S x r /+, \mathrm{XX}$ and normal mice are actually comparing cell populations of different origin, morphology and function; but the younger the animals, the more similar are the cell populations which are being compared.

The fact that both G6PD and PGK are coded for by genes on the X chromosome should not be relevant to this study. Although $S x r /+, \mathrm{XX}$ mice have two $\mathrm{X}$ chromosomes, we are considering only somatic cells in these animals and there is no reason to think that normal $X$ inactivation does not occur in these cells to leave only a single $\mathrm{X}$ genetically active. There is likewise no evidence that the activity of X-linked enzymes such as G6PD decreases in germinal cells following the inactivation of the $X$ chromosome at meiosis (Erickson, 1976; Brock, 1977).

Our experiments have shown that the specific activity of G6PD in the testis of $S x r /+, \mathrm{XX}$ mice is significantly higher than normal in young and adult mice. We have previously shown that high G6PD activity is characteristic of immature Sertoli cells, but not of either mature Sertoli cells or interstitial cells (Jones \& Andrews, 1978). In the $S x r /+, \mathrm{XX}$ animals, the adult level of G6PD activity in the testis resembles that in immature testes, suggesting that the Sertoli cells have not matured. This in turn suggests that the decrease in G6PD activity in Sertoli cells of normal mice reflects some interaction with the germinal cells. This' conclusion finds support in the histochemical studies of Ito (1966), showing that staining for G6PD around the periphery of the tubules increased after irradiation had caused the disappearance of the germinal cells, and in the work of Kormano, Härkönen \& Kontinen (1964) which showed that the G6PD activity of the tubules, as shown by histochemical staining, increased after experimental cryptorchidism in the rat.

Our measurements of PGK activity in testes of normal mice agree with those of Erickson (1977) in showing a large increase in activity during development, but in our mice this increase seemed to come rather earlier (30-40 days), and to be greater in magnitude.

Normal testis has two isoenzymes of PGK: PGK A, which is coded for by a gene on the X chromosome, and PGK B which is coded for by a gene on chromosome 17 (Vandeberg et al., 1976; Cherry \& Eicher, 1976). After electrophoresis of whole testis extracts, the bands for PGK $A$ and PGK B are of approximately equal intensity, and Vandeberg et al. (1976) considered that PGK B represents the contribution of the later stages of the germinal cells to the total activity, because PGK B is the predominant form in semen. We have found no evidence of any PGK B activity by electrophoresis of testicular extracts of $S x r /+, \mathrm{XX}$ mice and it is therefore surprising that the total PGK activity of the testis of adult $S x r /+, \mathrm{XX}$ animals is the same as that of the normal testis. However, the level of PGK activity in the immature $S x r /+, \mathrm{XX}$ mouse, even at young ages when the cell populations of the testes of normal and $S x r /+, \mathrm{XX}$ mice are more similar, is also rather higher than that of the normal testis. This observation indicates that the testis cells in young $\mathrm{Sxr} /+, \mathrm{XX}$ mice are in some way abnormal.

There is similarity in the developmental patterns of testicular G6PD and PGK in $\mathrm{Sxr} /+, \mathrm{XX}$ mice. While in normal mice, testis G6PD activity decreases and the PGK activity increases during the course of maturation in $\mathrm{Sxr} /+, \mathrm{XX}$ mice, the level of both enzymes stays about the same in both young and old mice. This suggests that the development of the somatic cells is 
arrested, perhaps because of the lack of germinal cells. It will be important to determine whether these abnormal patterns of development of testis enzymes are peculiar to $S x r /+, \mathrm{XX}$ mice, or whether they are also true of the testes of other mice which lack germinal cells, e.g. mice of the $\mathrm{W}^{\mathrm{v}} / \mathrm{W}^{\mathrm{n}}$ genotype for which there is evidence that the morphological development, at least, of the Sertoli cells is normal (Nagano, Suzuki, Kitamura \& Matsumoto, 1977).

The measurements of enzyme activity in the seminal vesicles of $S x r /+, \mathrm{XY}$ mice, their $\mathrm{Sxr} /+, \mathrm{XY}$ littermates and normal littermates indicated that the lack of germinal cells in the former does not affect the level of these two enzymes in this accessory sex gland. These observations support the view that the $S x r /+, \mathrm{XX}$ mice are normal phenotypic males except for their lack of germinal cells.

The measurements of G6PD and PGK in the livers of these three groups of mice show an intriguing similarity of pattern although none of the differences between groups is significant. The livers of the $S x r /+, \mathrm{XX}$ mice had the highest mean activity of both enzymes, the $S x r /+, \mathrm{XY}$ livers had intermediate, and the normal XY livers had lowest activity. Both these enzymes are part of the glycolytic pathway, and there seems to be no reason to expect any differences in the enzyme activities. Further work, including measurements of normal female livers $(+/+, X X)$, is required to clarify this point.

\section{References}

Bellvé, A.R., Cavicchia, J.C., Millette, C.F., O'Brien, D.A., Bhatnagar, Y.M. \& Dym, M. (1977) Spermatogenic cells of the prepuberal mouse, isolation and morphological characterization. J. Cell Biol. 74, $68-85$.

Bergmeyer, H.U. (1974) Methods of Enzymatic Analysis, 2nd English edn. Verlag Chemie, Weinheim.

Brock, W.A. (1977) Evidence against gene expression after meiosis in the male mouse. J. exp. Zool. 202, 68-80.

Cattanach, B.M. (1975) Sex-reversal in the mouse and other mammals. In The Early Development of Mammals, pp. 305-317. Eds M. Balls \& A. E. Wild. Cambridge University Press.

Cattanach, B.M., Pollard, C.E. \& Hawkes, S.G. (1971) Sex-reversed mice: $\mathrm{XX}$ and $\mathrm{XO}$ males. Cytogenetics 10, 318-337.

Cherry, M. \& Eicher, E. (1976) In Mouse News Letter $54,41$.

Erickson, R.P. (1976) Glucose-6-phosphate dehydrogenase activity changes during spermatogenesis: possible relevance to $\mathrm{X}$-chromosome inactivation. Devl Biol. 54, 134-137.

Erickson, R.P. (1977) Gene expression of a region of chromosome 17 during murine spermatogenesis. J. Immunogenetics 4, 353-362.

Flickinger, C.J. (1967) The postnatal development of the Sertoli cells of the mouse. Z. Zellforsch. mikrosk. Anat. 78, 93-113.

Gilula, N.B., Fawcett, D.W. \& Aoki, A. (1976) The Sertoli cell occluding junctions and gap junctions in mature and developing mammalian testis. Devl Biol. 50, 142-168.

Gondos, B. (1977) Testicular development. In The Testis, Vol. IV, pp. 1-37. Eds A. D. Johnson \& W. R. Gomes. Academic Press, London.

Hartree, E.F. (1972) Determination of protein: a modification of the Lowry method that gives a linear photometric response. Analyt. Biochem. 48, 422427.

Ito, M. (1966) Histochemical observations of oxidative enzymes in irradiated testis and epididymis. Radiat. Res. 28, 266-277.

Jones, J.T. \& Andrews, S.J. (1978) Glucose-6-phosphate dehydrogenase activity in somatic and germinal cells of the mouse testis. J. Reprod. Fert. 54, 357-362.

Kormano, M., Härkönen, M. \& Kontinen, E. (1964) Effect of experimental cryptorchidism on the histochemically demonstrable dehydrogenases of the rat testis. Endocrinology 74, 44-51.

Lowry, O.H., Rosebrough, N.J., Farr, A.L. \& Randall, R.J. (1951) Protein measurement with the Folinphenol reagent. J. biol. Chem. 193, 265-275.

Nagano, T., Suzuki, F., Kitamura, Y. \& Matsumoto, K. (1977) Sertoli cell junctions in the germ cell-free testis of the congenic mouse. Lab. Invest. 36, 8-17.

Shen, R.-S. \& Lee, I.P. (1976) Developmental patterns of enzymes in mouse testis. J. Reprod. Fert. 48, 301-305.

Vandeberg, J.L., Cooper, D.W. \& Close, P.J. (1976) Testis specific phosphoglycerate kinase B in mouse. J. exp. Zool. 198, 231-240.

Received 23 October 1978 